\title{
APPARATUS FOR DEMAND ANALGESIA
}

\author{
M. KeERI-Szanto, M.D. *
}

Post-OPERATIVE PAIN relief is conventionally provided by parenteral medication. The physician sets the dose and the minimum interval between injections: Within these limits the patient controls the amount of drug administered by calling for a needle whenever he becomes uncomfortable. This arrangement has stood the test of time in millions of applications but pain relief is less than complete in a fair percentage of subjects following major surgery. The breakdown is usually due to too conservative prescriptions or to long delays between the request for medication and the drug's absorption into the blood stream. In an effort to improve patient care, modes of demand analgesia have been investigated in several centers and various apparatus have been described ${ }^{1-3}$ that will allow safe self-administration of pain-killers. To this line we wish to add an account of the equipment developed in this department, in the belief that it represents a useful compromise between financial and space considerations on the one hand and safety plus the generation of information on the other.

The principle consists of putting the analgesic into a motor syringe and driving the motor through a switch-box that can be triggered by a push-button in the patient's hand (Figure 1). The box contains two timer-circuits: Circuit A, variable from 1 to 30 seconds, activates the motor syringe and after it has run its course it sets off circuit B, variable from 1 to 30 minutes, that blocks circuit $A$ for a set length of time. In addition, the box also contains pilot lights, a beeper, and a counter that are activated by the push-button and are not blocked by circuit $\mathrm{B}$. The motor syringe itself need not be complex, a single speed, single direction machine will do the job as long as it accepts a 20- to 30-ml disposable syringe and delivers from it $1 \mathrm{ml}$ in about 15 seconds. This equipment has been used in 60 patients to date, usually in a Recovery Room but occasionally on the wards as well. It costs in the vicinity of $\$ 1,000$ and has performed to our full satisfaction.

In contrast to other models the machine does not monitor the patency of the intravenous drip, this remains the duty of the nursing personnel and great care is taken of course to secure the right kind of intravenous line. There is no direct write-out, this is replaced in the Recovery Room by a warning light that shines as long as timer в is in motion, alerting the nurse that a new analgesic dose has to be charted. On the ward the dials are read and charted hourly, this activity fits easily into the nursing routine. As with all other apparatus of this kind it is unavoidable that a large, potentially lethal amount of narcotic is hooked up to the patient at certain times. Various fail-safe devices assure that this does not get accidentally injected in one bolus: there is no gravity feed or syphoning off involved, powerfailure will stop the machine, the circuitry is not affected by the patient "freezing" on the push-botton, the motor syringe's power has been so chosen that it will stall when the intravenous line is obstructed rather than inject the analgesic upstream

\footnotetext{
'Department of Anaesthesia, University of Western Ontario and Victoria Hospital, London, Ontario. 


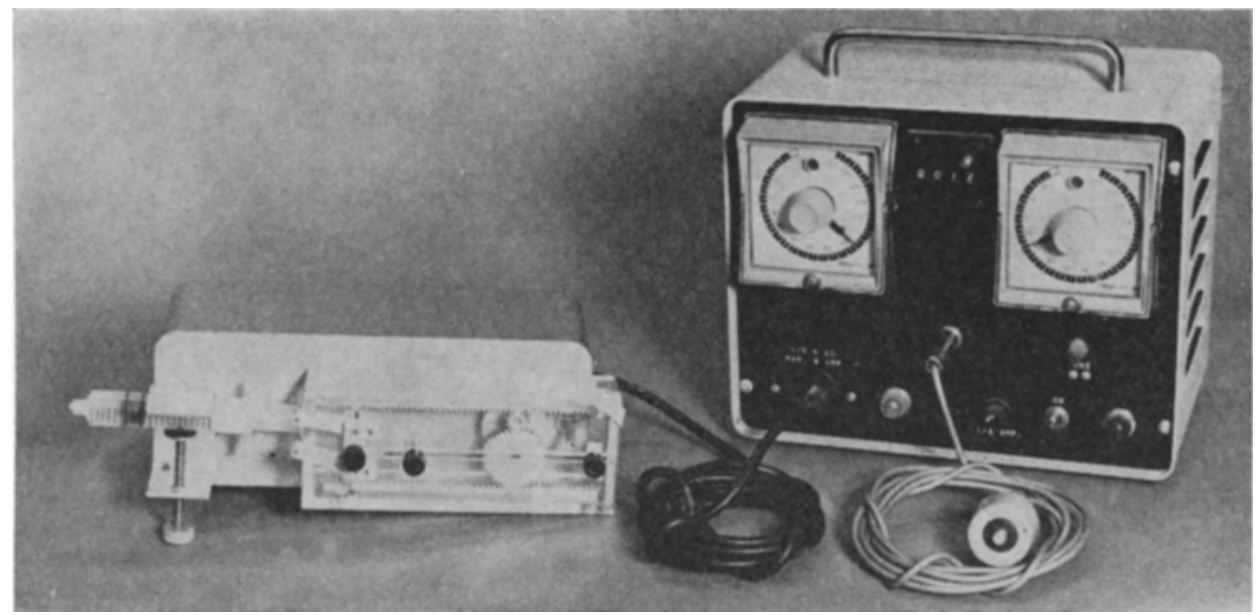

Figure 1. The complete apparatus. Left: The motor syringe. Right: The switchbox. Top array, lft to rt.: Timer A, counter, timer $\mathbf{B}$. The dark circles at 12 o'clock on timer dials are pilot lights. Middle array, lft. to rt.: push-button lead, beeper light. Bottom array, lft. to rt.: motor syringe socket, motor syringe circuit pilot light, fuse, on-off switch, switch-box circuit pilot light. Wiring diagram may be obtained by applying to the manufacturer-Canadian Algor Ltd, 159 Albert Street, London, Canada.

into the intravenous bottle. The timer-contacts are rated for 1,000 years of continuous use. The only theoretical possibility for accidental overdosage is the seizing of timer A's motor in the "on" position. This could be eliminated by adding a second, safety timer to circuit $\mathrm{A}$ but in view of the timer's rating and established performance in other, equally sensitive applications this was not thought necessary.

Calculations that will be published separately ${ }^{4}$ suggest that demand analgesia is at its most advantageous when the patient triggers the machine no more than two or three times per hour and receives a small amount of analgesic each time in response. This arrangement usually requires the injection of $0.2 \mathrm{mg}$ meperidine per $\mathrm{kg}$ or its equivalent (e.g. pentazocine $0.1 \mathrm{mg}$ or morphine $0.02 \mathrm{mg}$ ) at any one time and blocking the syringe for 15 minutes thereafter. The timer settings are very simple to change but this has rarely been necessary.

In our experience ${ }^{5}$, conventional pain relief following abdominal and thoracic operations is associated with substantial residual pain in about twenty per cent of our patients. The exact pathological or psychological significance of this complication remains to be defined: Its incidence can be reduced to less than five per cent however by the use of demand analgesia. The technique is well received by patients and surgeons and it offers the added promise of clearer insight into the pharmaco-kinetics of pain relief.

\section{REFERENCES}

1. Scotr, J. S. Obstetric Analgesia. Am. J. Obst. Gyn., 106: 959 (1970).

2. Forrest, W. H.; SMethurst, P. W. R.; \& Kienitz, M. E. Self-Administration of Intravenous Analgesics. Anesthesiology, 33: 363 (1970).

3. Sechzer, P. H. Studies in Pain with the Analgesic-Demand System. Anesth. \& Analg., 50: 1 (1971).

4. Keeri-Szanto, M. The Pharmaco-Kinetics of Postoperative Pain-Relief. To be published.

5. Keeri-Szanto, M.; \& Heaman, S. Postoperative demand-analgesia. Surg. Gyn. Obst. To be published March 1972. 